\title{
Estimation of Crystalline Junction Size of Linear High-Density Polyethylene Gel Comprised of Lamellae
}

\author{
Masaru OKABE ${ }^{\dagger}$ and Akira TAKAHASHI* \\ Department of Applied Chemistry, Faculty of Engineering, Kanagawa Institute of Technology, 1030 \\ Shimo-ogino, Atsugi, Kanagawa 243-0292, Japan \\ * Professor Emeritus, Mie University, Tsu, Mie 514-8507, Japan
}

(Received February 6, 1998)

\begin{abstract}
A method for estimating junction point size in a thermoreversible gel made up of overlapping lamellae with disc-like morphology is proposed by combining the theory of melting temperature depression of copolymer-diluent system with the continuum percolation theory which takes account of the excluded volume of disc. According to our method, junction point size of gel can be estimated from measurement of gel-melting temperature $T_{\mathrm{m}}{ }^{\mathrm{g} *}$ at the critical gelation concentration $v_{\mathrm{c}}$. This method was applied to linear high-density polyethylene (LHDPE)/xylene gel. The junction point size estimated by the present method, i.e., diameter and thickness of disc-like lamellae in a LHDPE gel, was in reasonable agreement with measurement by scanning electron microscopy (SEM) and small-angle X-ray scattering (SAXS) measurement.

KEY WORDS Thermoreversible Gel / Polyethylene / Linear High-Density Polyethylene / Continuum Percolation Theory / Junction Size of Lamella / Gel-Melting Temperature /
\end{abstract}

The sol-gel transition of polyolefin in organic solvents is well known. ${ }^{1,2}$ Gelation of such crystalline polymer takes place through formation of a network structure with crystalline junctions. In the case of semi-crystalline polymer gels such as random copolymer gel of ethylene and propylene including high content of propylene units (i.e., lots of methyl branchings), fringed micelle-type crystallite was appropriate morphology for the junction point. ${ }^{3}$ In the case of highly crystalline polymer gels such as linear high-density polyethylene (LHDPE) gel, junction points were disc-like lamellae with diameter $2 r$ and thickness $d$, which were three-dimensionally in contact with the others at random array as shown in Figure 1.4

Recently, site-bond percolation process was applied to gelation, because percolation has close similarity to sol-gel transition. Elastic behavior near the threshold $\left(C^{*}\right)$ of gelatin or casein gel has been investigated ${ }^{5,6}$ in detail by the bond percolation theory using the relation $E \propto\left[\left(C-C^{*}\right) / C^{*}\right]^{t}$ and critical exponent $(t)$ has been compared with that by the classical theory (i.e., the tree approximation), where $E$ is the elastic modulus and $C^{*}$ is the critical gelation concentration.

The site-bond percolation theory was developed basing upon a lattice model. Thus this theory cannot be applied directly to the system where particles such as lamellar or spherulitic crystals behave as junction points or loci, because the theory does not take the excluded volume effect of the particles into consideration. To such a system that contains the particles, application of the continuum percolation theory is more appropriate. In this theory, the excluded volume of the particles is taken into account.

This study proposes a new method for estimating the size of lamellar junction in a thermoreversible gel by combining the theory of melting temperature depression of crystallites, formulated by Takahashi and co-workers, ${ }^{7}$ with the continuum percolation theory. The present method is applied to the LHDPE/xylene gel in order to

\footnotetext{
+ To whom all correspondence should be addressed.
}

estimate the lamella size ( $2 r$ and $d$ shown in Figure 1).

\section{THEORETICAL}

According to Balberg, the critical occupied volume fraction $v_{\mathrm{c}}$ of particles at gelation point (i.e., the critical gelation concentration) is given by ${ }^{8}$

$$
v_{\mathrm{c}}=1-\exp \left[-B_{\mathrm{c}} V /\left\langle V_{\mathrm{ex}}\right\rangle\right]
$$

where $B_{\mathrm{c}}$ is the average critical number of bonds per site (i.e., $B_{\mathrm{c}}$ is the $Z \rightarrow \infty$ limit value of $P_{\mathrm{c}}^{\mathrm{s}} Z$ in the site percolation theory, where $P_{\mathrm{c}}^{\mathrm{s}}$ is the critical site-occupation probability of the lattice and $Z$ is the coordination number), $V$ is the volume of the particle, and $\left\langle V_{\mathrm{ex}}\right\rangle$ is the excluded volume of the particle.

In this study, we regard lamellae in Figure 1 as discs with diameter $2 r$ and thickness $d$ (see Figure 2). In the case of quenched gel, an amorphous layer may exist at the surface of crystalline sequence of lamella as shown in Figure 2(b), and thus the lamella thickness $d$ is given by

$$
d=d_{\mathrm{c}}+d_{\mathrm{a}}=d X_{\mathrm{c}}+d\left(1-X_{\mathrm{c}}\right)
$$

where $d_{\mathrm{c}}$ and $d_{\mathrm{a}}$ are the thicknesses of crystalline sequence (crystalline layer) and amorphous layer, respectively, and $X_{\mathrm{c}}$ is the degree of crystallinity of the lamella.

The volume of the disc $V$ illustrated in Figure 2(b) is given by

$$
V=\pi r^{2} d
$$

and the excluded volume $\left\langle V_{\text {ex }}\right\rangle$ is calculated by applying geometric probability theory (integral geometry for the disc of $d \ll r)^{9}$ as

$$
\left\langle V_{\text {ex }}\right\rangle \cong \pi^{2} r^{3}
$$

Introducing eq 3 and 4 into eq 1, we obtain

$$
v_{\mathrm{c}}=1-\exp \left(-\frac{B_{\mathrm{c}} d}{\pi r}\right)
$$

Since lamella thickness $d$ is very small as compared with 


\section{Lamellae in LHDPE/Xylene Gel}

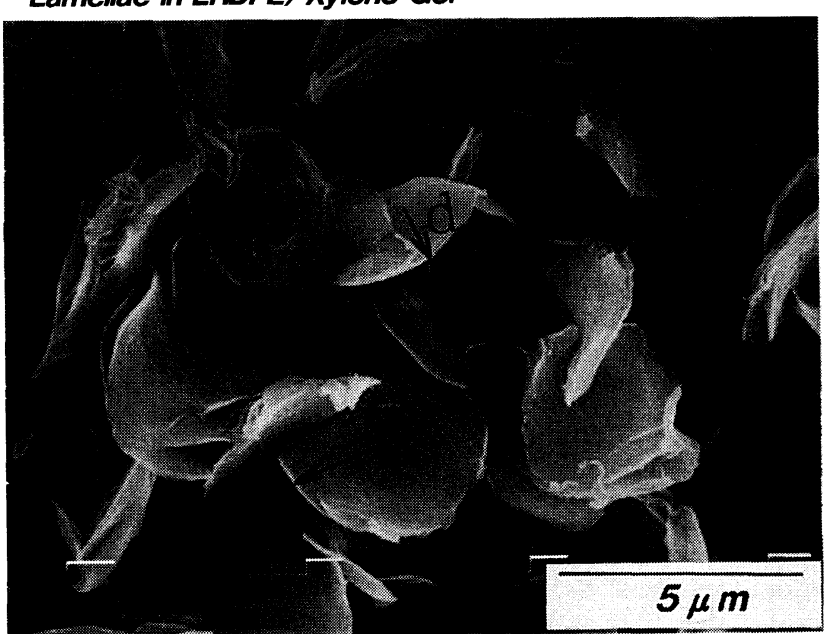

Figure 1. SEM photograph of disc-like lamellae formed in linear high-density polyethylene/xylene gel. This is enlarged morphology of Figure 4.

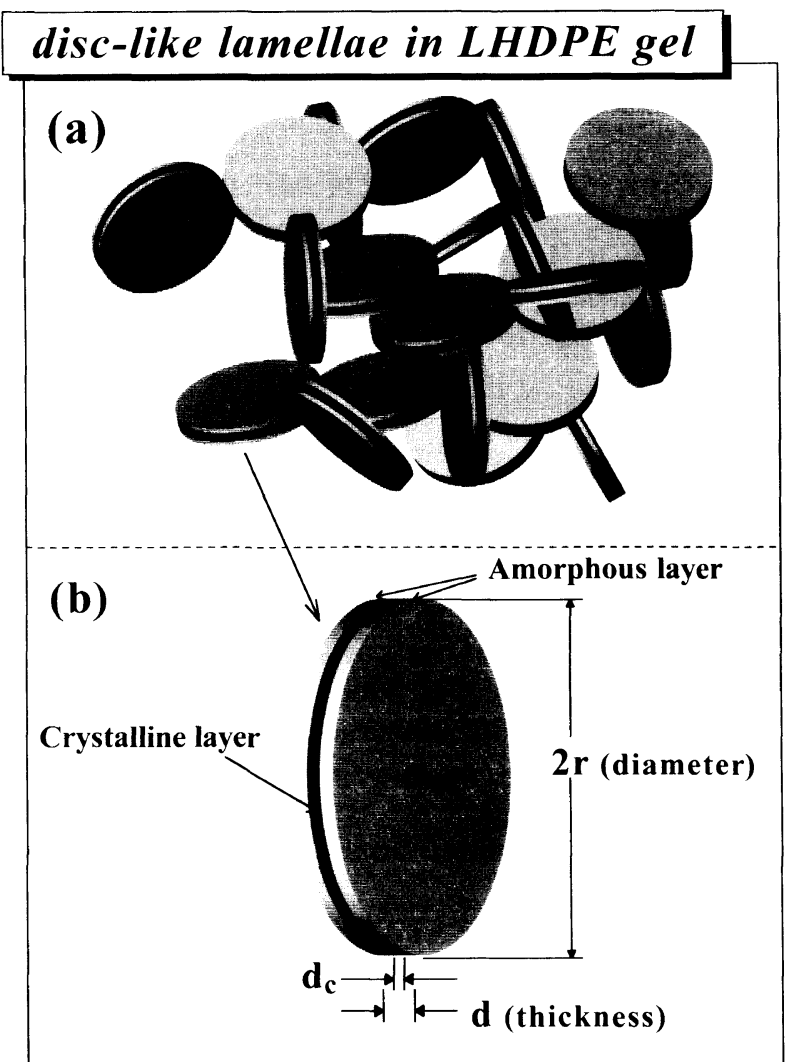

Figure 2. Schematic drawing of junction model composed of overlapping lamellae at random array.

its radius $r$ (i.e., $d \ll r)$, eq 5 can be approximated to the equation

$$
v_{\mathrm{c}}=1-\left[1-\frac{1}{1 !}\left(\frac{B_{\mathrm{c}} d}{\pi r}\right)+\frac{1}{2 !}\left(\frac{B_{\mathrm{c}} d}{\pi r}\right)^{2}-\cdots\right] \cong \frac{B_{\mathrm{c}} d}{\pi r}
$$

Experimentally, of course, the lamella thickness $(d)$ can be measured by small-angle X-ray scatttering (SAXS) and the radius of lamella $(r)$ can be measured by scanning electron microscopy (SEM). However, our aim is to estimate both $d_{\mathrm{c}}$ and $r$ from the observed critical gelation concentration $v_{\mathrm{c}}$ and gel-melting temperature $T_{\mathrm{m}}{ }^{\mathrm{g} *}$ at $v_{\mathrm{c}}$ without resorting to measurement of SAXS and SEM.

According to Balberg ${ }^{8}$ and Charlaix, ${ }^{10} B_{\mathrm{c}}$ is a universal constant under a given shape of objects. Thus, $d$ and $d_{\mathrm{c}}$ are obtained from eq 6 as

$$
\begin{aligned}
& d=\pi r v_{\mathrm{c}} / B_{\mathrm{c}} \\
& d_{\mathrm{c}}=d X_{\mathrm{c}}=\pi r v_{\mathrm{c}} X_{\mathrm{c}} / B_{\mathrm{c}}
\end{aligned}
$$

It should be noted that eq 7 and 8 only hold at the critical gelation concentration $v_{\mathrm{c}}$.

We require a relationship between the melting temperature $T_{\mathrm{m}}$ of a nonequilibrium lamellar crystallite and its thickness $d_{\mathrm{c}}$ characterized by the interfacial free energy $\sigma_{\mathrm{ec}}$. The following equation obtained by Takahashi and co-workers, ${ }^{7}$ which was derived for melting temperature depression of copolymer-diluent system, is applicable to lamellar crystallite with thickness $\zeta($ i.e.,$\zeta=$ $\left.d_{\mathrm{c}}\right)$ :

$$
\begin{aligned}
\frac{1}{T_{\mathrm{m}}}- & \frac{1}{T_{\mathrm{m}}{ }^{0}}=\frac{R}{\Delta H_{\mathrm{u}}}\left[\left(\frac{V_{\mathrm{A}}}{V_{1}}\right)\left(1-v_{2}\right)+\frac{v_{2} V_{\mathrm{A}}}{x \bar{V}}-\frac{1}{\zeta} \ln v_{2}\right. \\
& \left.+\frac{2 \sigma_{\mathrm{ec}}}{\zeta R T_{\mathrm{m}}}-\frac{1}{\zeta} \ln \left(\frac{x-\zeta+1}{x}\right)-\ln X_{\mathrm{A}}-\chi^{\prime}\left(1-v_{\mathrm{A}}\right)^{2}\right] \\
= & \frac{R^{\prime}}{\Delta h_{\mathrm{f}}} \frac{1}{d_{\mathrm{c}}}\left[\frac{2 \sigma_{\mathrm{ec}}^{\prime}}{R^{\prime} T_{\mathrm{m}}}-\ln v_{2}\right]+\frac{R}{\Delta H_{\mathrm{u}}}\left[\left(\frac{V_{\mathrm{A}}}{V_{1}}\right)\left(1-v_{2}\right)\right. \\
& \left.+\frac{v_{2} V_{\mathrm{A}}}{x V}-\frac{1}{\zeta} \ln \left(\frac{x-\zeta+1}{x}\right)-\ln X_{\mathrm{A}}-\chi^{\prime}\left(1-v_{\mathrm{A}}\right)^{2}\right]
\end{aligned}
$$

where

$\zeta:$ crystallite size in number of repeating units; $d_{\mathrm{c}} / \mathrm{cm}$ : lamella thickness of crystalline sequence; $R /$ cal K ${ }^{-1} \mathrm{~mol}^{-1}$ and $R^{\prime} / \mathrm{erg} \mathrm{K}^{-1} \mathrm{~cm}^{-2}$ : gas constants; $\Delta H_{\mathrm{u}} / \mathrm{cal} \mathrm{mol}^{-1}$ and $\Delta h_{\mathrm{f}} / \mathrm{erg} \mathrm{cm}^{-3}$ : enthalpies of fusion per repeating unit;

$\sigma_{\mathrm{ec}} / \mathrm{cal} \mathrm{mol}^{-1}$ and $\sigma_{\mathrm{ec}}^{\prime} / \mathrm{erg} \mathrm{cm}^{-2}$ : end interfacial free energy per crystalline sequence;

$T_{\mathrm{m}}{ }^{0} / \mathrm{K}$ : equilibrium melting temperature of a pure infinite size crystal;

$T_{\mathrm{m}} / \mathrm{K}$ : melting ( i.e., dissolution) temperature of polymer-diluent system;

$x$ : number of repeating units per polymer chain (degree of polymerization);

$v_{1}$ : volume fraction of solvent;

$v_{2}$ : volume fraction of polymer;

$V_{\mathrm{A}} / \mathrm{cm}^{3} \mathrm{~mol}^{-1}, \quad \bar{V} / \mathrm{cm}^{3} \mathrm{~mol}^{-1}$, and $V_{1} / \mathrm{cm}^{3} \mathrm{~mol}^{-1}$ : molar volumes of crystallizable unit, of average copolymer unit, and of solvent, respectively;

$X_{\mathrm{A}}:$ mole fraction of crystallizable units;

$\chi^{\prime}$ : thermodynamic interaction parameter;

$v_{\mathrm{A}}$ : volume fraction of crystallizable units.

When $x$ is large and if $\zeta \ll x$, eq 10 can be approximated to

$$
\begin{aligned}
& \frac{1}{T_{\mathrm{m}}}-\frac{1}{T_{\mathrm{m}}{ }^{0}} \cong \frac{R^{\prime}}{\Delta h_{\mathrm{f}}} \frac{1}{d_{\mathrm{c}}}\left[\frac{2 \sigma_{\mathrm{ec}}^{\prime}}{R^{\prime} T_{\mathrm{m}}}-\ln v_{2}\right] \\
& +\frac{R}{\Delta H_{\mathrm{u}}}\left[\left(\frac{V_{\mathrm{A}}}{V_{1}}\right)\left(1-v_{2}\right)-\ln X_{\mathrm{A}}-\chi^{\prime}\left(1-v_{\mathrm{A}}\right)^{2}\right]
\end{aligned}
$$


Since $X_{\mathrm{A}}=1, v_{\mathrm{A}}=v_{2}$, and $V_{\mathrm{A}}=\bar{V}$ for homopolymer, eq 11 is written as

$$
\begin{aligned}
\frac{1}{T_{\mathrm{m}}}-\frac{1}{T_{\mathrm{m}}{ }^{0}}= & \frac{R^{\prime}}{\Delta h_{\mathrm{f}}} \frac{1}{d_{\mathrm{c}}}\left[\frac{2 \sigma_{\mathrm{ec}}^{\prime}}{R^{\prime} T_{\mathrm{m}}}-\ln v_{2}\right] \\
& +\frac{R}{\Delta H_{\mathrm{u}}}\left[\left(\frac{\bar{V}}{V_{1}}\right) v_{1}-\chi^{\prime} v_{1}{ }^{2}\right]
\end{aligned}
$$

where $v_{1}$ is the volume fraction of solvent and $v_{1}=1-v_{2}$.

Equilibrium dissolution temperature $T_{\mathrm{s}}{ }^{0}$ of pure infinite size crystallite in a solvent can be estimated ${ }^{11}$ when $d_{\mathrm{c}} \rightarrow \infty$ in eq 12 and thus eq 12 is written as

$$
\frac{1}{T_{\mathrm{m}}^{0}}-\frac{1}{T_{\mathrm{s}}{ }^{0}}=-\frac{R}{\Delta H_{\mathrm{u}}}\left[\left(\frac{\bar{V}}{V_{1}}\right) v_{1}-\chi^{\prime} v_{1}^{2}\right]
$$

Eliminating the undiluted equilibrium melting temperature $T_{\mathrm{m}}{ }^{0}$ from eq 12 and 13, we obtain for homopolymer

$$
\frac{1}{T_{\mathrm{m}}}-\frac{1}{T_{\mathrm{s}}{ }^{0}}=\frac{R^{\prime}}{\Delta h_{\mathrm{f}}} \frac{1}{d_{\mathrm{c}}}\left[\frac{2 \sigma_{\mathrm{ec}}^{\prime}}{R^{\prime} T_{\mathrm{m}}}-\ln v_{2}\right]
$$

At the gel-melting temperature with critical gelation concentration $v_{\mathrm{c}}$, letting $T_{\mathrm{m}}=T_{\mathrm{m}}{ }^{\mathrm{g} *}$ and $v_{2}=v_{\mathrm{c}}$, eq 14 is rewritten as follows to obtain lamella thickness $\left(d_{\mathrm{c}}\right)$ :

$$
d_{\mathrm{c}}=\frac{R^{\prime}}{\Delta h_{\mathrm{f}}}\left[\frac{2 \sigma_{\mathrm{ec}}^{\prime}}{R^{\prime} T_{\mathrm{m}}{ }^{\mathrm{g} *}}-\ln v_{\mathrm{c}}\right]\left[\frac{T_{\mathrm{m}}{ }^{\mathrm{g} *} T_{\mathrm{s}}{ }^{0}}{T_{\mathrm{s}}{ }^{0}-T_{\mathrm{m}} \mathrm{g}^{\mathrm{g}}}\right]
$$

The radius of lamella $(r)$ can be determined by rewriting eq 8 using $d_{\mathrm{c}}$ in eq 15 as

$$
r=\frac{d_{\mathrm{c}} B_{\mathrm{c}}}{\pi v_{\mathrm{c}} X_{\mathrm{c}}}
$$

In this study, the gel-melting temperature $T_{\mathrm{m}}{ }^{\mathrm{g} *}$ at the critical gelation concentration $v_{\mathrm{c}}$ of LHDPE/xylene system and the degree of crystallinity $X_{c}$ of lamellae formed in the gel are measured, and junction size of lamella $\left(d_{\mathrm{c}}\right.$ and $r$ ) is estimated from eq 15 and 16 making use of the reported values of $T_{\mathrm{s}}{ }^{0}, \sigma_{\mathrm{ec}}^{\prime}$, and $\Delta h_{\mathrm{f}} . d_{\mathrm{c}}$ and $r$, thus estimated, are compared with those obtained by measurement of SEM and SAXS.

\section{EXPERIMENTAL}

\section{Materials}

Four samples of unfractionated LHDPE, supplied by Showa Denko Co., were used. These samples are homopolymers. The densities of the samples, weight-average molecular weights $\left(\bar{M}_{w}\right)$, and melting temperatures $\left(T_{\mathrm{m}}\right)$ are listed in Table I. Each sample was dissolved completely in xylene (concentration: $c a .2 \mathrm{wt} / \mathrm{vol} \%$ ) at the boiling point under reflux, and then precipitated into excess cooled methanol, and finally dried under reduced pressure at $40^{\circ} \mathrm{C}$.

Xylene was used as the gelation solvent. It was shaken several times with concentrated sulfuric acid, followed by repeated washing with distilled water. It was then dried with calcium chloride and fractionally distilled.

\section{Preparation of Gel}

A gel was prepared in a sealed glass tube with $c a$. $30 \mathrm{~cm}$ length and $1 \mathrm{~cm}$ diameter as follows: A definite amount of sample was dissolved completely in $5 \mathrm{~cm}^{3}$ of
Table I. Physical properties of linear high-density polyethylenes

\begin{tabular}{lcccc}
\hline \multirow{2}{*}{ Sample } & Density & & & $T_{\mathrm{m}}{ }^{\mathrm{b}}$ \\
\cline { 2 - 3 } & $\mathrm{g} \mathrm{cm}^{-3}$ & & & \\
& & & & \\
& & & \\
& & \\
& & & \\
LHDPE8 & 0.960 & 7.9 & 5.8 & 131.2 \\
LHDPE11 & 0.941 & 11.1 & 6.4 & 121.1 \\
LHDPE13 & 0.940 & 12.6 & 6.9 & 124.3 \\
LHDPE14 & 0.946 & 13.7 & 8.0 & 130.3 \\
\hline
\end{tabular}

${ }^{\mathrm{a}} \bar{M}_{w}$, weight-average molecular weight determined by GPC. ${ }^{\mathrm{b}} T_{\mathrm{m}}$, melting temperature measured by DSC.

xylene at $160^{\circ} \mathrm{C}$. The sample tube was quenched into an ice bath at $0^{\circ} \mathrm{C}$ for $2 \mathrm{~h}$ to prepare a gel.

\section{Critical Gelation Concentration and Gel-Melting Tem- perature}

To estimate lamella thickness $\left(d_{\mathrm{c}}\right)$ from eq 15 and radius of lamella $(r)$ from eq 16 , critical gelation concentration $\left(v_{\mathrm{c}}\right)$ and gel-melting temperature $\left(T_{\mathrm{m}}{ }^{\mathrm{g} *}\right)$ at $v_{\mathrm{c}}$ must be determined experimentally. Measurement of $v_{\mathrm{c}}$ was carried out as follows: A hot solution $\left(160^{\circ} \mathrm{C}\right)$ with given concentration in a sealed glass tube was quenched at $0^{\circ} \mathrm{C}$, and maintained for $2 \mathrm{~h}$. A steel ball of $c a .2 \mathrm{mg}$ weight was then put on the surface of the LHDPE/xylene system in the glass tube to examine whether it would ride or not. If so, such a system was defined as a gel. When the steel ball rode on the surface of gel layer, the same measurement was repeated lowering the polymer concentration. Minimum polymer concentration at which the steel ball would not fall was taken as the critical gelation concentration $v_{\mathrm{c}}$.

Gel-melting temperature was measured by the fallingball method using the above glass tube. A gel was heated at $c a .0 .3^{\circ} \mathrm{C} \mathrm{min}^{-1}$ and $T_{\mathrm{m}} \mathrm{g} *$ was determined as in the previous study. ${ }^{4}$

\section{$X$-Ray Measurement}

To determine the degree of crystallinity $X_{\mathrm{c}}$ of lamellae, wide-angle X-ray diffraction (WAXD) measurement was carried out using a Rigaku X-ray diffractometer, Model RINT-2500VHF, with an experimental condition of 50 $\mathrm{kV}$ and $200 \mathrm{~mA}$. Lyophilized gels were used as specimens and diffraction patterns were recorded using $\mathrm{Cu}-K_{\alpha}$ radiation with wavelength $\lambda=0.15405 \mathrm{~nm}$.

SAXS measurement was carried out with a position sensitive proportional counter and a rotating anode $\mathrm{X}$ ray generator. SAXS intensity distribution was recorded by point focus with a three-slit system as a function of $2 \theta$ and the long spacing (an alternate distance $d_{\mathrm{c}}$ of lamella in Figure 2(b)) was evaluated from the $2 \theta$ position of the SAXS intensity maximum.

\section{Scanning Electron Microscopy (SEM)}

Morphology observation was carried out using a JEOL scanning electron microscope, Model JSM-T20. Lyophilized gels were used as specimens. As seen in Figure 1, lamellae have slight size distribution and thus the average value was taken as diameter $2 r$. 


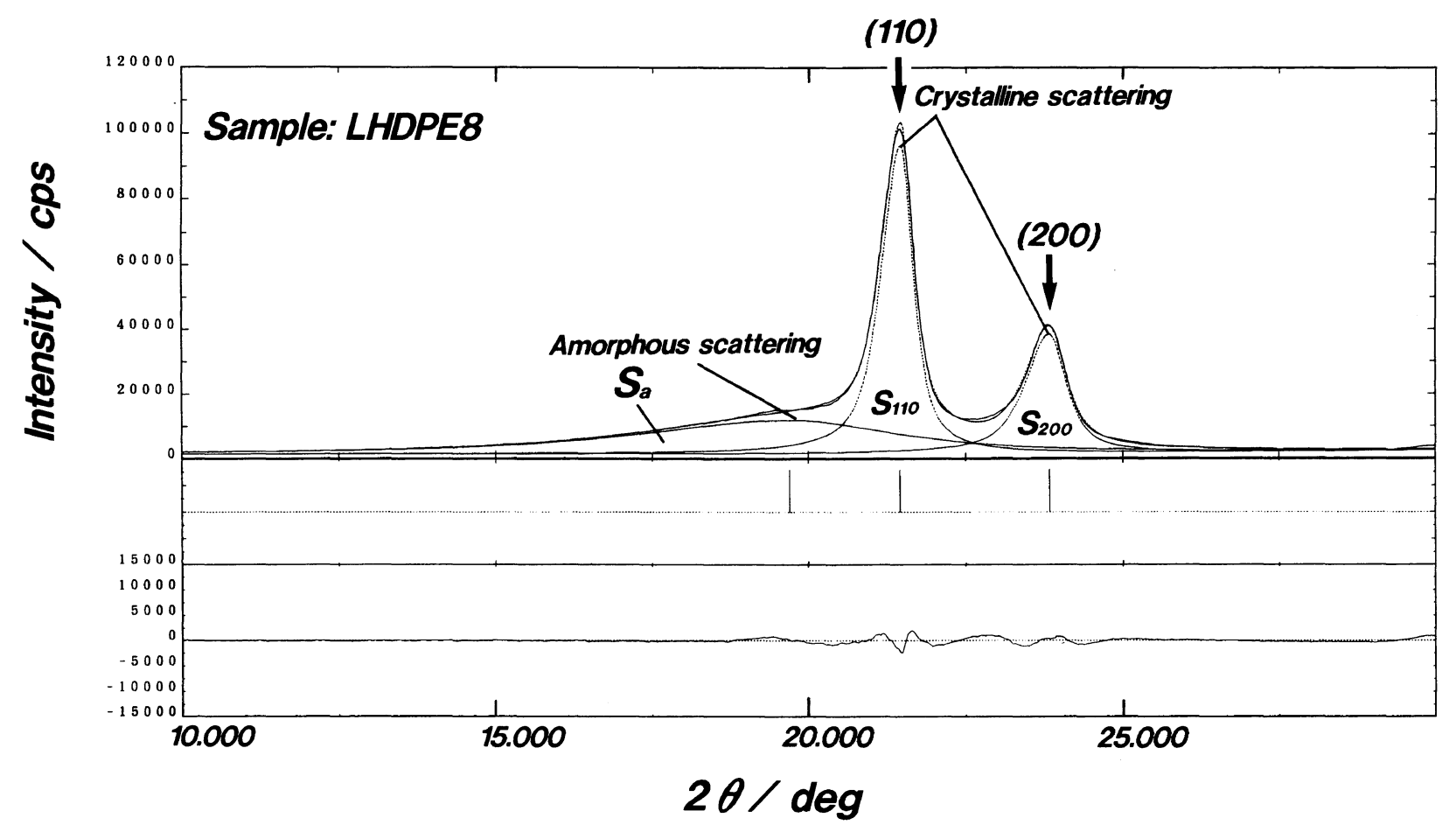

Figure 3. Relation between scattering intensity and diffraction angle $2 \theta$ for lyophilized LHDPE8/xylene gel.

\section{Gel-Melting Temperature of LHDPE8/Xylene System}

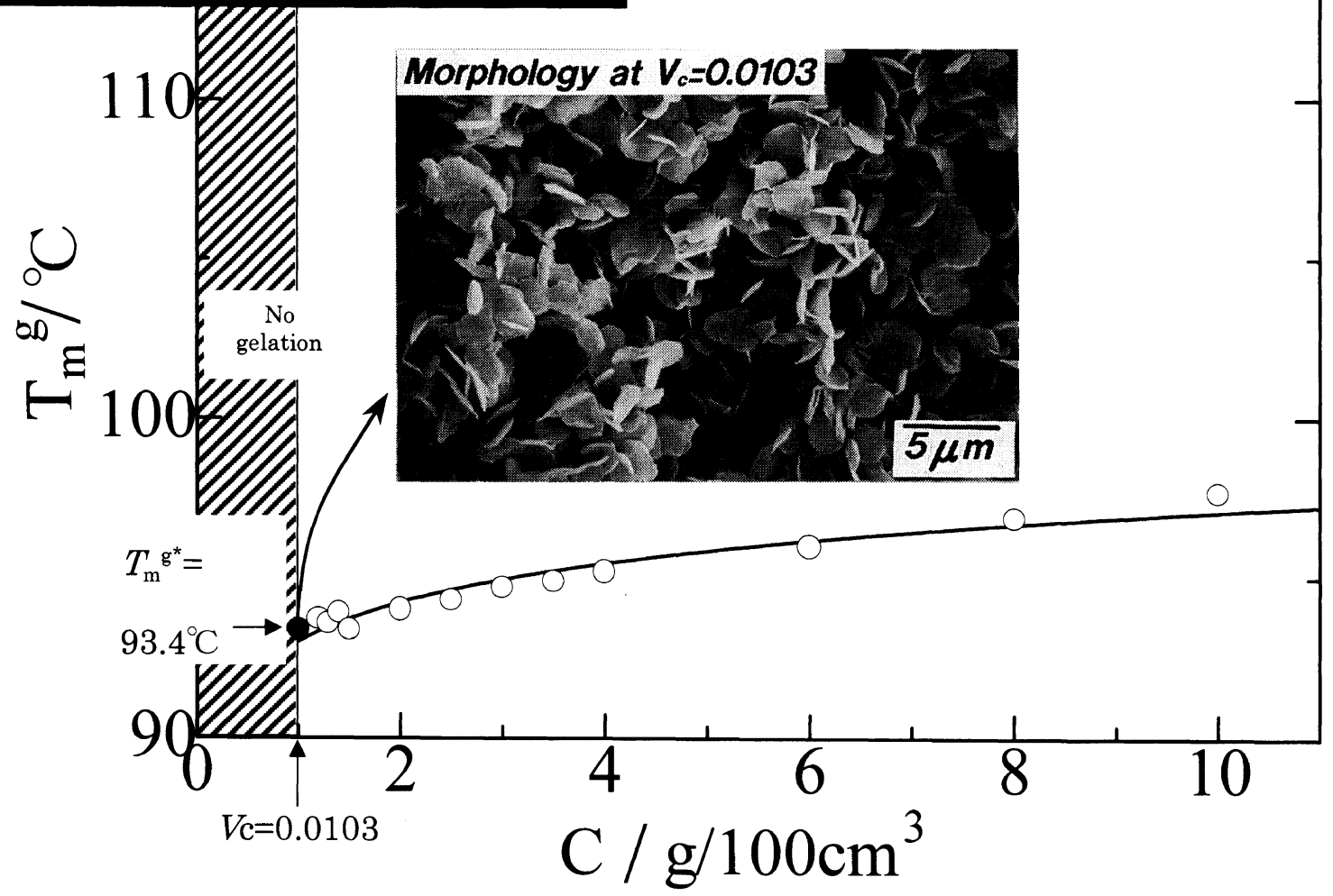

Figure 4. Relation between gel-melting temperature $T_{\mathrm{m}}{ }^{\mathrm{g}}$ and polymer concentration $C$ for LHDPE8/xylene gel. The morphology in this figure was observed by SEM at the critical gelation concentration, $v_{\mathrm{c}}$.

\section{RESULTS AND DISCUSSION}

Degree of Crystallinity $\left(X_{\mathrm{c}}\right)$

An example of diffraction pattern by WAXD measurement is shown in Figure 3, which is the pattern of 886
Table II. Values of parameters in eq 15 and 16

$\begin{array}{ll}B_{\mathrm{c}} & 2 \\ \Delta h_{\mathrm{f}} & 2.80 \times 10^{9} \mathrm{erg} \mathrm{cm}^{-318} \\ R^{\prime} & 7.304 \times 10^{-2} \mathrm{erg} \mathrm{K}^{-1} \mathrm{~cm}^{-2}\end{array}$


Table III. Lamella size in LHDPE/xylene gel

\begin{tabular}{|c|c|c|c|c|c|c|c|}
\hline \multirow{3}{*}{ Sample } & \multirow{3}{*}{$X_{\mathrm{c}}$} & \multirow{3}{*}{$v_{\mathrm{c}}$} & \multirow{3}{*}{$\frac{T_{\mathrm{m}}^{\mathrm{g} *}}{{ }^{\circ} \mathrm{C}}$} & \multicolumn{2}{|c|}{ By the present method } & \multirow{3}{*}{$\begin{array}{c}\text { by SEM } \\
\frac{2 r}{\mu \mathrm{m}}\end{array}$} & \multirow{3}{*}{$\frac{\text { by SAXS }}{\frac{d_{\mathrm{c}}}{\AA}}$} \\
\hline & & & & $2 r$ & $d_{\mathrm{c}}$ & & \\
\hline & & & & $\mu \mathrm{m}$ & $\AA$ & & \\
\hline LHDPE8 & 0.62 & 0.0103 & 93.4 & $3.6 \pm 0.3$ & $179 \pm 2$ & $3.4 \pm 0.4$ & $138 \pm 3$ \\
\hline LHDPE11 & 0.52 & 0.0204 & 88.3 & $1.7 \pm 0.5$ & $139 \pm 3$ & $1.5 \pm 0.3$ & $110 \pm 5$ \\
\hline LHDPE13 & 0.53 & 0.0094 & 90.5 & $4.1 \pm 0.2$ & $161 \pm 3$ & $4.5 \pm 0.4$ & $143 \pm 5$ \\
\hline LHDPE14 & 0.63 & 0.0106 & 90.8 & $3.5 \pm 0.2$ & $163 \pm 2$ & $4.9 \pm 0.4$ & $135 \pm 5$ \\
\hline
\end{tabular}

lyophilized LHDPE8/xylene gel. According to the ordinary method, ${ }^{12}$ the degree of crystallinity $X_{\mathrm{c}}$ can be calculated from the ratio of integrated crystalline scattering to the total scattering as

$$
X_{\mathrm{c}}=\frac{1.0\left(S_{110}\right)+1.46\left(S_{200}\right)}{1.0\left(S_{110}\right)+1.46\left(S_{200}\right)+0.75\left(S_{\mathrm{a}}\right)}
$$

where $S_{110}$ and $S_{200}$ are the areas of crystalline scattering curves on planes (110) and (200), respectively, and $S_{\mathrm{a}}$ is the area of amorphous scattering curve. Values of $X_{\mathrm{c}}$, thus calculated, are listed in Table III.

\section{Gel-Melting Temperature $T_{\mathrm{m}}{ }^{\mathrm{g} *}$ at $v_{\mathrm{c}}$}

The relation between gel-melting temperature $T_{\mathrm{m}}{ }^{\mathrm{g}}$ and polymer concentration $C$ for the system LHDPE8/xylene is shown in Figure 4. In dilute solution below $c a .1 .0 \mathrm{~g}$ $100 \mathrm{~cm}^{-3}$, crystalline precipitates were separated from the solution without formation of a gel. A region where a gel was not formed is shown by oblique lines in Figure 4. The critical gelation concentration $v_{\mathrm{c}}$ (symbol: $)$ ) and gel-melting temperature $T_{\mathrm{m}}{ }^{\mathrm{g} *}$ at $v_{\mathrm{c}}$ are listed in Table III.

\section{Estimation of Lamella Size in Gel}

To estimate the radius $(r)$ of lamella from eq 16, we must assume the numerical value of $B_{\mathrm{c}}$. Recently, computer simulation by the Monte Carlo method has been carried out for overlapping objects such as discs [for example, see Figure 2(a)] or spheres to estimate the numerical value of $B_{\mathrm{c}}$.

According to Balberg, ${ }^{8} B_{\mathrm{c}}$ is universal and independent of the size distribution and orientation distribution of objects with a given shape in the system. Spherical shape has the highest $B_{\mathrm{c}}$ and widthless-stick shape has the lowest $B_{\mathrm{c}}$. Charlaix carried out a numerical evaluation of $B_{\mathrm{c}}$ for a random array of discs, and simulated to $B_{\mathrm{c}}=1.80$ for the discs. ${ }^{10}$ So, we use here $B_{\mathrm{c}} \cong 2$ for lamellae in LHDPE/xylene gel, because each lamella has two wide surfaces.

The values of end interfacial free energy $\sigma_{\mathrm{ec}}^{\prime}$ for linear polyethylenes have been measured by many investigators and found to be scattered widely. ${ }^{13-18}$ In this study, we used the value $\sigma_{\mathrm{ec}}^{\prime}=93 \pm 8 \cong 100 \mathrm{erg} \mathrm{cm}^{-2}$. For $T_{\mathrm{s}}{ }^{0}$, the equilibrium dissolution temperature of LHDPE in xylene, we used the reported value of $T_{\mathrm{s}}{ }^{0}=391.75 \mathrm{~K} .{ }^{11}$ Besides $\sigma_{\mathrm{ec}}^{\prime}$ and $T_{\mathrm{s}}^{0}$, numerical values of other parameters in eq 15 and 16 are shown in Table II.

Thickness $\left(d_{\mathrm{c}}\right)$ and diameter (2r) of lamella, a junction point of LHDPE gel, were calculated from eq 15 and 16, and are summarized in Table III. As seen in Table III, the lamella size $2 r$ and $d_{\mathrm{c}}$ estimated by the present

Polym. J., Vol. 30, No. 11, 1998 method are reasonable compared with those observed by SEM and SAXS measurement. Accordingly, the present method makes it possible to evaluate simultaneously the two morphological quantities $d_{\mathrm{c}}$ and $r$ which characterize the junction point (or loci) of LHDPE gel from simple measurement of $T_{\mathrm{m}}{ }^{\mathrm{g} *}$ at $v_{\mathrm{c}}$ without relying upon SAXS and SEM measurement. This is the most significant point of this study.

Differences in lamella size $\left(d_{\mathrm{c}}\right)$ by the present method and by SAXS measurement are attributed to the magnitude of $\sigma_{\mathrm{ec}}^{\prime}$. This study used the reported value $\left(\sigma_{\mathrm{ec}}^{\prime} \cong\right.$ $\left.100 \mathrm{erg} \mathrm{cm}^{-2}\right)^{13-18}$ without differences in crystallite size or molecular weight of polyethylene samples. The effect of lamella thickness on the melting temperature of polyethylene leads to evaluation of $\sigma_{\mathrm{ec}}^{\prime} \cong 90-300 \mathrm{erg}$ $\mathrm{cm}^{-2}$ depending on molecular weight. ${ }^{11,16,17}$ Theoretical calculation by Flory, Yoon, and Dill ${ }^{19}$ gave $\sigma_{\mathrm{ec}}^{\prime} \cong 55-70$ $\mathrm{erg} \mathrm{cm}^{-2}$. If we use $70 \mathrm{erg} \mathrm{cm}^{-2}$ as $\sigma_{\mathrm{ec}}^{\prime}$, we obtain the coincidence of $d_{\mathrm{c}}$ obtained by SAXS measurement and the present method. However, $2 r$ is (about $20 \%$ ) reduced.

In conclusion, the continuum percolation theory which takes account of the excluded volume effect of objects is well applicable to LHDPE gels where lamellar crystallites behave as junction points.

Acknowledgment. The authors express their sincere appreciation to Dr. Hirohisa Yoshida of Tokyo Metropolitan University for his assistance in making SAXS measurements.

\section{REFERENCES}

1. H. Matsuda, K. Araki, H. Fujimatsu, and S. Kuroiwa, Polym. J., 13, 587 (1981).

2. R. C. Domszy, R. Alamo, C. O. Edwards, and L. Mandelkern, Macromolecules, 19, 310 (1986).

3. a) M. Okabe, K. Mitsui, H. Uranaka, M. Takahashi, and H. Matsuda, Polym. J., 24, 653 (1992); b) M. Okabe, Y. Moteki, H. Uranaka, M. Takahashi, and H. Matsuda, Polym. J., 25, 955(1993); c) Y. Moteki, M. Okabe, M. Takahashi, and H. Matsuda, Polym. J., 26, 1002 (1994).

4. M. Okabe, K. Mitsui, and H. Matsuda, Kobunshi Ronbunshu, 46, 681 (1989).

5. For example, P. G. de Gennes, "Scaling Concepts in Polymer Physics," Part A, Cornell University Press, Ithaca, N. Y., 1979, Chapter V (Polymer Gels).

6. M. Tokita, R. Niki, and K. Hikichi, J. Chem. Phys., 83, 2583 (1985).

7. A. Takahashi, T. Nakamura, and I. Kagawa, Polym. J., 3, 207 (1972).

8. I. Balberg, Phil. Mag. B, 56, 991 (1987).

9. K. M. Jansons and C. G. Phillips, J. Colloid Interface Sci., 137, 75 (1990)

10. E. Charlaix, J. Phys. A: Math. Gen., 19, L533 (1986).

11. For example, J. F. Jackson, L. Mandelkern, and O. C. Long, 
Macromolecules, 1, 218 (1968).

12. For example, J. F. Rabek, "X-Ray Diffraction Analysis," in "Experimental Methods in Polymer Chemistry," Wiley-Interscience, New York, N. Y., 1980, Chapter 28.

13. J. F. Jackson and L. Mandelkern, Macromolecules, 1, 546 (1968).

14. F. R. Anderson, J. Appl. Phys., 35, 64 (1964).

15. L. Mandelkern, J. Polym. Sci., C, 15, 129 (1966).

16. L. Mandelkern, J. M. Price, M. Gopalan, and J. G. Fatou, J.
Polym. Sci., A-2, 4, 385 (1966).

17. J. M. Schultz, W. H. Robinson, and G. M. Pound, J. Polym. Sci., $A-2, \mathbf{5}, 511$ (1967).

18. M. J. Richardson, P. J. Flory, and J. B. Jackson, Polymer, 4, 221 (1963).

19. P. J. Flory, D. Y. Yoon, and K. A. Dill, Macromolecules, 17, 862 (1984). 